\title{
Informing the information requirements of a digital twin: a rail industry case study
}

\author{
Aaron Johnson \\ Jacobs, Network Rail Offices, York, UK (corresponding author: \\ aaronjohnjohson@hotmail.com) \\ James Heaton \\ Institute for Manufacturing, Department of Engineering, University of \\ Cambridge, Cambridge, UK \\ Steven Yule \\ Jacobs, Network Rail Offices, York, UK \\ Sam Luke \\ Jacobs, London, UK
}

\author{
David Pocock \\ Jacobs, London, UK \\ Ajith Kumar Parlikad \\ Institute for Manufacturing, Department of Engineering, University of \\ Cambridge, Cambridge, UK \\ Jennifer Schooling \\ Centre for Smart Infrastructure and Construction, Department of \\ Engineering, University of Cambridge, Cambridge, UK
}

The right data to the right people at the right time are a crucial component to developing an effective digital twin (DT). A challenge in the industry is that existing legacy data systems have been tailored independently to meet specific technical requirements, leading to disparate information systems that collectively provide a suboptimal foundation needed to support a modern digital environment. To address this challenge, a detailed study was conducted in partnership with Network Rail to test a method that was adapted for the industry to identify appropriate, relevant and effective asset information requirements (AIRs). A robust library of AIRs will determine what data the organisation should be collecting and why these are necessary through design, construction, operation and disposal, hence informing the information requirements of a DT. The methodology was modified with four adaptations to improve its compatibility with the industry and was tested with 24 subject matter experts in the rail sector. It was concluded that integration of the AIR method would ensure that the rail industry is well positioned for digital transformation and provides a solid foundation to develop a DT. However, industry integration of the method would be a significant undertaking due to the amount of information that needs to be considered throughout the process, and so further research is required to improve its scalability.

\section{Introduction}

A challenge in the industry is that existing legacy data systems have been tailored independently to meet specific technical requirements, which has led to information being siloed, usually by discipline (Moore and Starr, 2006). Many organisations today manage multiple disparate information systems that collectively generate a suboptimal foundation needed to support a modern digital environment. In addition, a modern data environment will need to be dynamic and adapt to organisational priorities such that a digital twin (DT) remains relevant and useful or otherwise risk being unrepresentative.

Therefore, in the age of the DT, it is crucial that an organisation has an agile process in place that can review and identify information requirements. This paper presents the industry application of a novel methodology for identifying appropriate, relevant and effective asset information requirements (AIRs). A robust library of AIRs will inform what data an organisation should be collecting and why these are necessary throughout design, construction, operation and disposal, hence informing the information requirements of a DT. The method tested in this case study builds on a seven-step process that was designed to bridge the gap between organisational objectives and AIRs by considering functional requirements (Heaton et al., 2019). A modified version of the approach was applied on the Transpennine Route Upgrade (TRU) Programme, a major railway enhancement project to improve connectivity between York and Manchester being delivered by Network Rail (2019a).

The paper contains seven proceeding sections. Section 2 gives a research overview on DTs and their role in the rail sector. Section 3 outlines the case study approach and research questions that form the premise of the study. Section 4 explains the adapted methodology tested in this study to inform the information requirements of a DT in industry. The case study steps of application are described in Section 5. Outputs from the study, benefits of approach application and key industry feedback are presented in Section 6, with proposed future research captured in Section 7. Finally, study findings are concluded in Section 8.

\section{Background}

This section provides background research on DTs and their role in the rail sector, helping shape the scope of the study.

\subsection{Literature review on DTs}

A DT in the context of the built environment aims to integrate different data sets from static files, such as building information modelling (BIM) to dynamic data sets such as information from condition monitoring systems. A popular definition of a DT in this context is 'a realistic digital representation of assets, processes or systems in the built or natural environment' (CDBB, 2019: p. 10). 
Smart Infrastructure and Construction

Volume 174 Issue 2
Informing the information requirements

of a digital twin: a rail industry case

study

Johnson, Heaton, Yule et al.
The Centre for Digital Built Britain (CDBB) was established in 2017 by the UK government at the University of Cambridge as a knowledge and innovation hub with the remit to take BIM to the 'next level'. The CDBB focuses on BIM and DTs within the domain of information and technology management, moving the focus away from the simplistic BIM levels of 1,2 and 3 into a whole-life approach to include design, construction, operation and disposal. This change in philosophy was also demonstrated by the transition from BIM Publicly Available Specifications to international standards by the International Organization for Standardization (ISO, 2018a, 2018b), which do not reference BIM levels to avoid confusion.

Furthermore, the CDBB has also developed a set of high-level value statements that aim to define the 'principles' of a National Digital Twin while maintaining a technology-agnostic approach that takes the form of nine value statements (see Figure 1).

There is a consensus within the literature that a DT is built on good-quality data (Lu et al., 2020a). This fact is reinforced by a report published by the UK National Infrastructure Commission (NIC, 2017: p. 7), which states 'high quality, standardised data on all our infrastructure assets, along with the ability to share this securely, will enable the UK's infrastructure to be viewed as an interdependent, dynamic system'.

Information management of physical assets within a system of systems is a complex and daunting task for asset-management organisations (Becerik-Gerber et al., 2011), which results in poor data interoperability (Gürdür and Asplund, 2018) and a fundamental lack of trust in the data (Kelly et al., 2013). Furthermore, there is a fundamental challenge in the development of information requirements, to support the development of an asset information model (AIM) and address information management and data quality challenges (Patacas et al., 2016).

While BIM goes some way to addressing this challenge, its adoption within the operational and maintenance (O\&M) phase has been limited (Navendren et al., 2015). Several examples within the BIM-related literature address both the data quality challenges and the Gemini principles. The development of an AIM is achieved through the use of open standards and technology to support building owners and facility managers (FMs) (Patacas et al., 2016). Using open standards provides limited guidance for ascertaining owners' requirements when building an AIM. This approach aligns with the Gemini principle of federation, by providing a federated model and openness by the sole use of open technology and standards. Another approach is the development of owner information requirements, a methodology specific to the development of owner requirements within the domains of BIM and so has limited application to wider organisational requirements (Cavka et al., 2017). Ashworth et al. (2016a) proposed a process to understand FM requirements within the information requirement stage. While FM input is important, it is not the only requirement that is needed, and solely focusing on FM risks limiting other requirements, such as financial or environmental requirements.

There are several attempts to design and validate the aspects of a DT. Lu et al. (2019) proposed a dynamic architecture for a DT at the building level that integrates data such as BIM, sensor data and assetmanagement data into a common application layer. Leng et al. (2019) proposed a DT architecture that also introduces an asset lifecycle stage that sees the DT mature over time within a selforganising decentralised approach. Madni et al. (2019) proposed a system model-based systems engineering approach to the
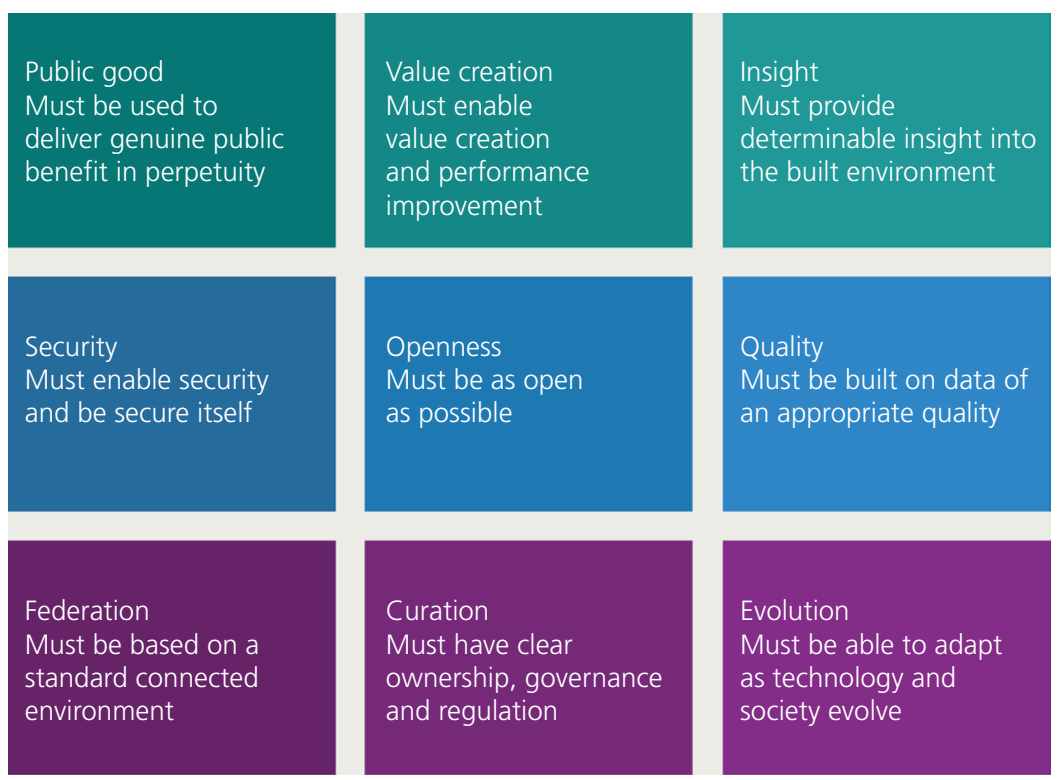

Figure 1. Gemini principles (CDBB, 2019) 
Smart Infrastructure and Construction

Volume 174 Issue 2
Informing the information requirements

of a digital twin: a rail industry case

study

Johnson, Heaton, Yule et al. development of a DT, specially looking at how a DT can be integrated into systems engineering tool suites, with the potential of systems engineering being a starting point for DT development. Souza et al. (2019) proposed a DT architecture that links directly with an Internet of things (IoT) gateway and therefore creates a direct link to physical assets. While this literature is helpful in the development of a DT, it is limited to specific technology solutions, with minimal consideration to the overall requirements of a DT or alignment with the Gemini principles (see Figure 1). There have been several attempts to utilise the aspects of a DT within the different life cycle stages of an asset, such as a DT-driven framework that enables feedback into the production/design phase (Tao et al., 2019), a proposed multi-level-of-detail approach to the simulation of the construction of an asset (Butkovic et al., 2019) and the use of a DT framework (including photogrammetry) to identify the anomalies and defects of an asset within the O\&M phase (Lu et al., 2020b). Finally, Boje et al. (2020) provided a detailed discussion on the direction of research for an engineering-related DT with the first generation of a DT focused on monitoring platforms such as IoT sensors, evolving into an intelligent semantic DT that allows for analytics and advanced artificial intelligence and finally an agent-driven sociotechnical DT that has end-user engagement, dynamic optimisation and learning capability.

It can be seen within the Gemini principles that DT has the potential to impact asset-management organisations positively from a financial, social and environmental perspective. There are several examples within the BIM domain that support the elements of a DT, but they are often manual and reactive processes that do not address the fundamental lack of detailed information requirements. This is despite the understanding that for a DT to generate value, it must be built on solid information-management processes.

Heaton et al. (2019) proposed an information requirement methodology that adopts the elements of BIM, asset management and requirements engineering (RE), providing a step-by-step approach to the development of information requirements within an asset-management organisation (see Figure 2). The authors

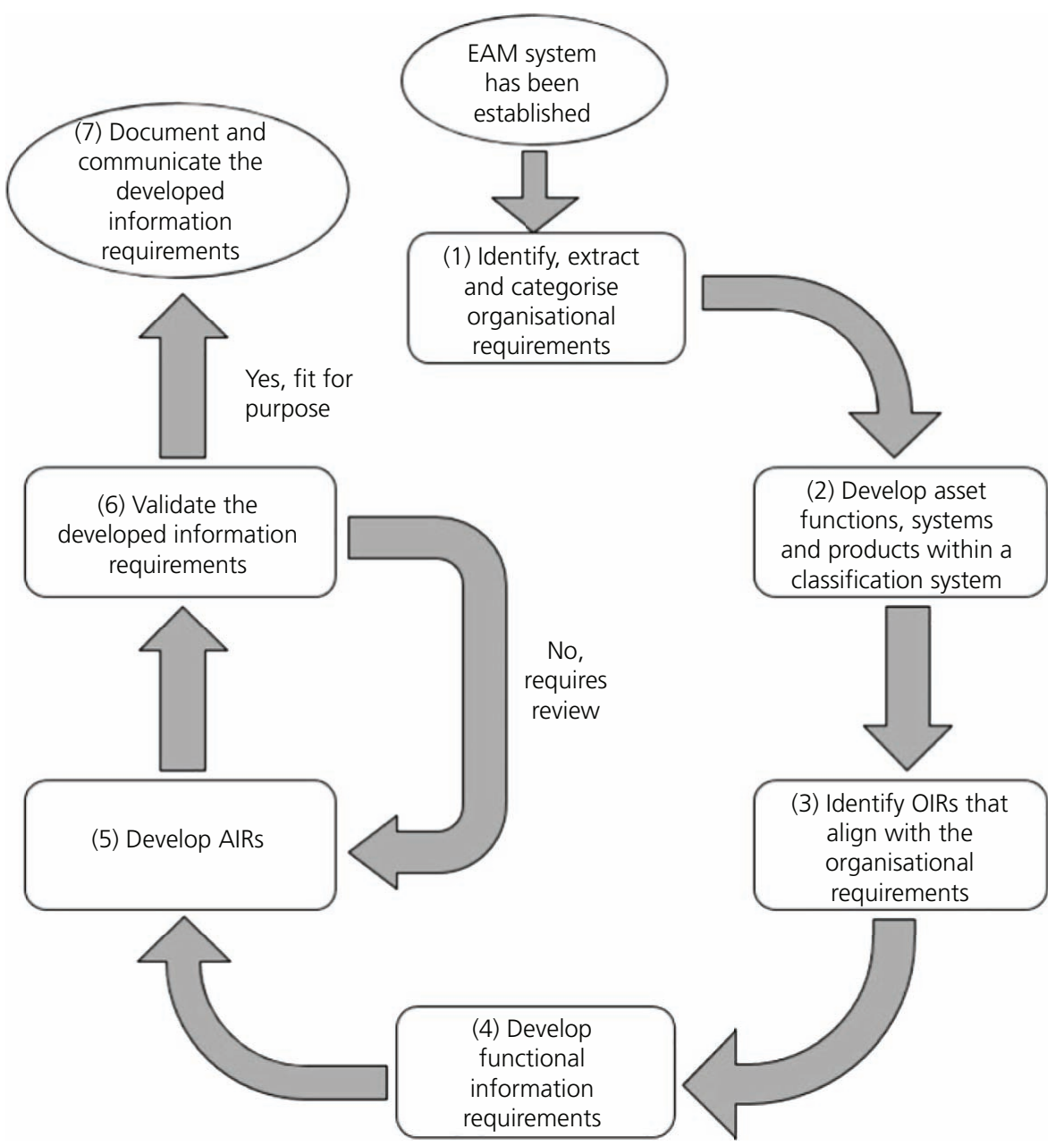

Figure 2. AlR method prior to adaptations (Heaton et al., 2019). Engineering asset management (EAM) is the development of a system for supporting the management of physical assets throughout their life cycle, in line with the asset-management standard ISO 55000 (ISO, 2014). OIRs, organisational information requirements 
Smart Infrastructure and Construction

Volume 174 Issue 2
Informing the information requirements

of a digital twin: a rail industry case

study

Johnson, Heaton, Yule et al. noted that with several modifications, the methodology could be optimised for use within an industry case study and support the development of DT information requirements.

\subsection{Review of information requirement development}

With the advancement of computer power in the 1950s and 1960s, organisations were promised enormous opportunities to streamline organisational processes and systems, in the form of information-management systems (IMSs). With this advancement, it was quickly realised that one cannot simply ask managers what information they require, as they will give bias to their own department requirements, therefore creating IMSs of little value (Ackoff, 1967). Furthermore, it is mistaken to assume that managers know what information they require for the decisionmaking process while evidence demonstrates the contrary (Wetherbe, 1991). By the early 1980s, RE had emerged as a research domain to address this challenge specifically. This includes the development of tools such as critical success factors (CSFs) (Rockart, 1979), business system planning (Zachman, 1982) and end/means analysis (Wetherbe and Davis, 1983), among others, that aid in providing a structured approach to developing information requirements.

Adoption of RE by asset owners has been limited. This is partly due to the late adoption of IMSs within the industry and general lack of information-management skills (Kelly et al., 2013), including the complexity of development information requirements for complex asset systems of systems that number in the thousands with multiple stakeholders. There have been several attempts to develop information requirements from an asset owner's perspective, such as engaging the asset maintainer within the early design stages (Ashworth et al., 2016b), categorising asset-related data (Becerik-Gerber et al., 2011) and the use of open BIM standards (such as the information delivery manual) (Patacas et al., 2015). These attempts developed improvised and limited information requirements, as they did not follow an RE approach, therefore limiting their application.

In general, it can be witnessed that for $\mathrm{RE}$ and information requirement development to be adopted by asset owners, specific methodologies and tools to support them.

\subsection{Rail industry investigation}

In the UK, the majority of railway infrastructure is owned and managed by Network Rail. Network Rail is data rich, with numerous different systems spread across the organisation. These systems have developed organically over a number of years to meet changing business requirements and priorities. The systems lack full integration and alignment, meaning that Network Rail struggles at times to make full use of the information opportunities potentially available.

There is an opportunity for Network Rail to use these data to improve its processes of design, operation and maintenance of the railway network to provide a safe, efficient, reliable and punctual service, resulting in good customer experiences. This requires a railway that is intelligent, that is digitally enabled, where data from the network can be used to make enhanced and evidence-based decisions to allow the right interventions to be made within a wholeof-life paradigm, to create, facilitate and sustain long-term value for the railway. A strategic approach to the development and implementation of DT offers Network Rail the opportunity to address these challenges and exploit the value of their data.

Current progress with DTs is in its infancy within Network Rail and the wider rail industry. This is partly driven by a relatively new awareness of DTs as a concept and a concern around the potential risk of associated hype. This has led to a high degree of interest that is at times tempered with sensible caution. The creation of a DT requires an ecosystem of hardware, software and suppliers, each element contributing to produce an outcome whose value is greater than the sum of its parts. There is no onesize-fits-all approach to DTs and the technology needed to meet an organisation's business objectives.

In the rail sector, the TRU Programme utilises the following working definition of DT: '[t]he digital combination of multiple static and real-time data sources, analytics and visualisations to provide enhanced understanding and insights across railway disciplines, systems and networks. Aligned to the imperative of Putting Passengers First'.

DT represents a step change for Network Rail in terms of how it fundamentally operates and meets its overall corporate objectives. There is now a tangible opportunity to create a more connected railway that is providing the right data, at the right time and to the right people.

\subsection{Background summary}

The literature review noted the fact that a DT is built of goodquality data, while the CDBB report noted (see Figure 1) that a DT needs to have a 'purpose' and should be developed only when there is a strategic need, such as social, financial, operational or environmental.

Furthermore, it was noted that while there is a domain of literature that is focused on the development of information requirements, most notably $\mathrm{RE}$, its adoption by asset owners is limited. This is partly due to the difficulty of developing information requirements for complex asset systems of systems.

Finally, the industry investigation noted that Network Rail is a 'data-rich' company with many decades' worth of engineering, asset performance and design data within multiple systems. It was also noted that the information captured is mostly from a technical perspective and has not changed to align it with the changing organisational vision and mission. Furthermore, the IMSs are often siloed within their own departments, with little integration with other systems. Therefore, gaining meaningful insight from the data is a challenge. 
Reflecting on the above, the development of information requirements is a challenge, particularly in the context of asset owners and operators. Furthermore, while research on DTs is growing, the focus is usually on specific applications or frameworks such as IoT sensors and data integration platforms and does not address the fundamental challenge of developing information requirements.

Therefore, there is a clear need for a methodology that addresses the challenge of developing information requirements within the domain of DTs to establish a purpose or strategic need.

\section{Case study methodology}

This section presents the research methodology and research objectives. A qualitative research approach in the form of a case study was adopted as information requirement development (and specifically RE) is commonly referred to as a branch of software engineering that is concerned with real-world wants and requirements.

\subsection{Research objective}

Considering the challenges identified within Section 2, the following research objective was developed to guide the case study, 'to develop a structured approach to the identification of information requirements that support the development of a digital twin'. This research objective was supported by two research questions. Research question 1 (RQ1) regards the adoption of an appropriate methodology to support the development of information requirements. The second research question (RQ2) focuses on using industry engagement to further current understanding on deploying an information requirement process in a business environment.

- RQ1: 'How can existing methodologies help support the development of information requirements within the context of a digital twin?'

- RQ2: 'How can engagement with the industry provide insight on modifications to enhance the methodology for real-world and practical application?'

The two research questions are reflected in the conclusion.

\subsection{Case study result validation}

The information requirements themselves are validated at the point of entry into the AIR web application. Table 1 provides a set of clarification statements that are used as a focused point to gain consensus among the participants of the workshop. Different classification statements are used depending on the level of information requirements being developed, such as organisational information requirement (OIR), functional information requirement (FIR) and AIR.

The performance of the case study was validated in the form of an industry survey where a total of 24 participants were asked to provide positive or negative feedback.

\section{AIR methodology and adaptations}

The case study implemented an adapted version of the seven-step process presented by Heaton et al. (2019) that bridges the gap from organisational objectives to AIRs. The methodology prior to adaptations is shown in Figure 2. The original seven-step approach to identifying AIRs was chosen as an appropriate starting point due to the following reasons.

- It uses a top-down approach that begins at the organisation level to identify what a DT is and the information it should contain. This provides a line of sight from strategic objectives set at the top of the organisation to the asset information recorded in the field, thus stating why that information is necessary.

- Consideration of the functional aspects of a given organisation encourages a holistic mindset where a combination of systems is usually required to produce a single functional output. Consideration of functional outputs bridges the gap between organisation objectives and AIRs.

- The methodology allows flexibility in its application, allowing an organisation to adapt the approach in a way that is suitable.

Four adaptations were implemented to the AIR method to improve its compatibility with the industry. The adapted AIR method is shown in Figure 3 and is the approach applied in the case study.

The adaptations were developed in line with interviews and informal conversations with industry professionals and research conducted during the industry investigation.

\subsection{Adaptation 1: asset classification}

The selected AIR method includes a step for the asset classification of functions, systems and products (step 2 of 7). Heaton et al. (2019) suggest employing a classification system such as Uniclass or OmniClass to assist with understanding the link between functional

Table 1. Validation process clarification statements according to AIR method steps

\begin{tabular}{|c|c|c|}
\hline Step number & Step description & Clarification statement to be satisfied \\
\hline 1 & $\begin{array}{l}\text { Organisational } \\
\text { requirements }\end{array}$ & Is the organisational objective Smart (specific, measurable, achievable, realistic and time-bound)? \\
\hline 2 & CSFS & Would failure in the CSF lead to the corresponding organisational objective not being met? \\
\hline 3 & Plain-language questions & $\begin{array}{l}\text { Would not answering the plain-language question lead to unknown consequences to the } \\
\text { associated CSF? }\end{array}$ \\
\hline 4 & Functional outputs & Does the functional output impact the answer to the plain-language question? \\
\hline 5 & Asset system & Would the absence of the asset system prevent the functional output from being obtained? \\
\hline
\end{tabular}



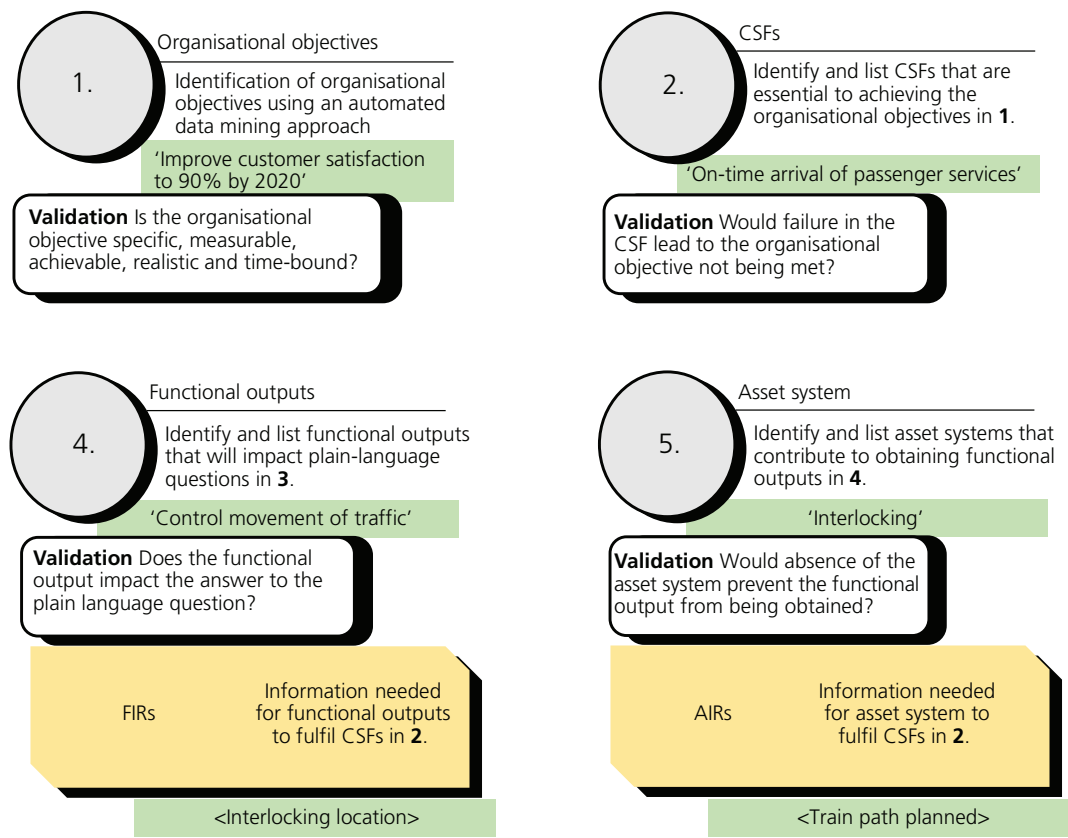

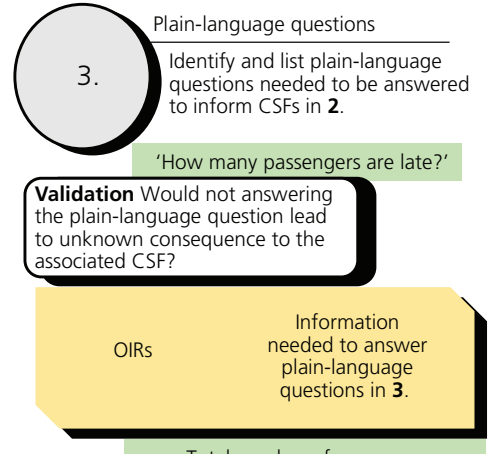

$<$ Total number of passengers $>$

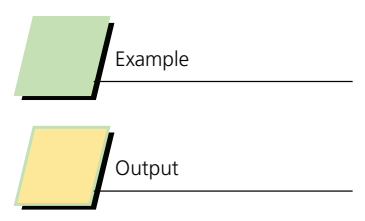

Figure 3. AIR method including adaptations

outputs and asset systems. However, completing steps 1, 3, 4 and 5 of the AIR method sequentially derives this link naturally, and so application of step 2 is not essential to the identification of appropriate, relevant and effective information requirements. In addition, completion of step 2 in most cases requires a significant amount of effort, which would draw attention away from the value that the AIR method would bring to the organisation. Early industry engagement made it clear that a method requiring a significant amount of effort would struggle to be recognised by the industry as a pragmatic solution. Therefore, the classification of assets using Uniclass or a similar approach has been removed as a core step to the method and is instead referenced as a suggestion to improve the quality of results.

\subsection{Adaptation 2: validation process}

Adaptation 2 concerns restructuring the method to conduct validation of inputs as and when captured. Conducting the validation in this way mitigates the risk of an error being carried through the entire process before a correction is implemented. The revised validation process requires fulfilment of a clarification statement unique to each step (see Figure 3) after the input of any new information. Clarification statements that should be satisfied at each step of process are given in Table 1 .

\subsection{Adaptation 3: extraction of organisational objectives}

Organisational objectives are contained in a number of document types, many of which can contain thousands of pages. In practice, the manual extraction of objectives from these documents would be a strenuous task prone to subjectivity and error. The third adaptation automates the process by utilising data mining techniques to classify text from a single or a collection of documents into separate discrete organisational objectives.

\subsection{Adaptation 4: utilisation of application software}

CSFs, plain-language questions (PLQs) and information requirements are identified using a workshop setting, requiring attendance of staff from all levels of the organisation who can vary greatly in expertise. The approach was amended to incorporate the use of a software application that distils the process from beginning to end into a readily available format, improving the efficiency of capturing inputs. The software application can then be used to support workshop discussions and to allow participants to complete the process outside the workshop setting. Microsoft Power Apps was the selected software application for the case study in this paper; however, there are many different solutions available that could be considered.

\section{Case study approach}

The case study was undertaken by researchers with extensive industry knowledge in the rail sector and was completed in partnership with Network Rail on the TRU Programme over a time frame of 4 months. A justification on why the rail industry and the TRU Programme provide an ideal platform for this case study is given in Section 2.

The scope of the case study was limited to applying steps 1-5 (Figure 3) on one Network Rail organisational objective, which was achieved by progressing through six milestones. Figure 4 visualises the relationship between milestone progress and application of the AIR method. Asset classification was not carried out, as it was deemed too big a task to undertake during this case study. However, the Uniclass hierarchy classifications 
Smart Infrastructure and Construction

Volume 174 Issue 2
Informing the information requirements

of a digital twin: a rail industry case

study

Johnson, Heaton, Yule et al.

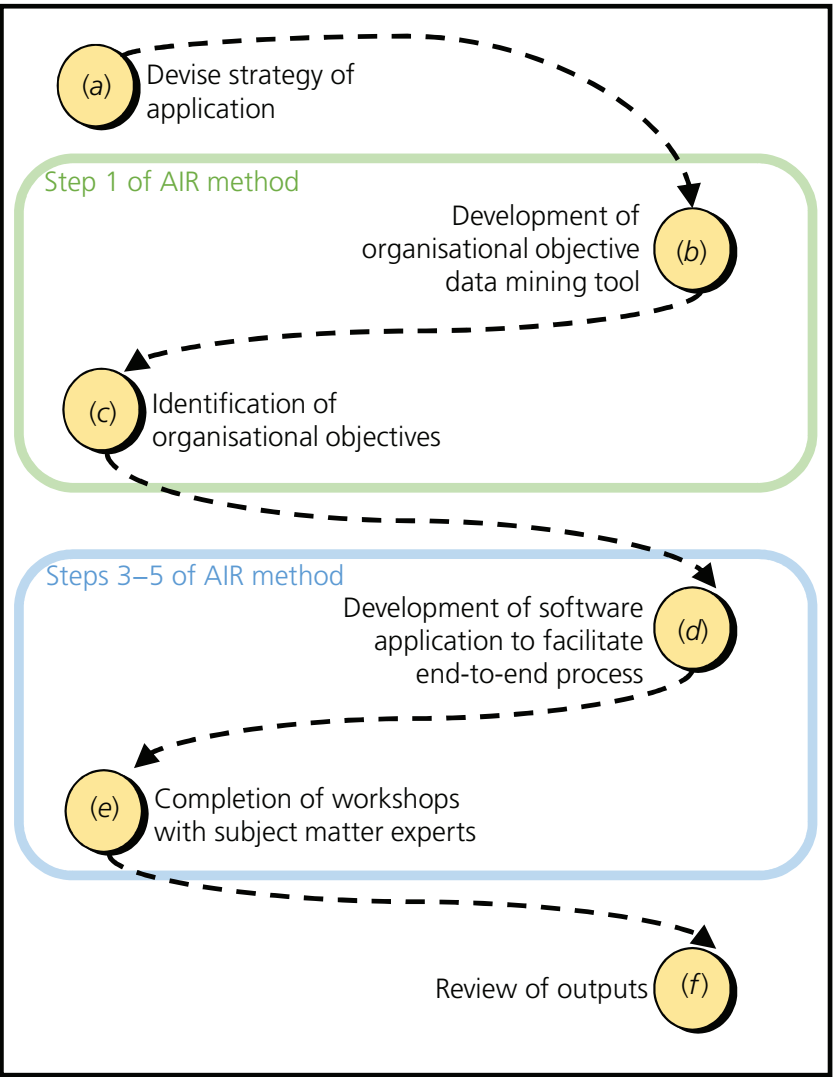

Figure 4. AIR method application milestones

were studied using resources provided by NBS (2015) to understand potential further improvements to case study results.

\subsection{Milestone 1: strategy of application}

The case study started by reviewing the complexities of the AIR method and associated risks, which informed how the method would be applied on the TRU Programme. One key risk to the success of the case study was the low attendance of workshops, which would be mitigated by developing a software application that improved participant interactivity and organising workshops in a timely manner.

After conducting an initial high-level review, two software packages were selected: one for applying a data mining classification algorithm to identify organisational objectives automatically and the second for developing a software application to make the process accessible to the industry and understandable to all. The algorithm for detecting organisational objectives was coded using Python. Python is opensource software, and so it requires no cost to implement. Microsoft Power Apps was chosen to develop the software application to distil the approach in an accessible end-to-end process. Power Apps and Python were selected to complement the existing skill set in the research team.

Finally, appropriate subject matter experts from all levels of the organisation were identified to participate in the workshops.
Participants were selected based on their job role, expertise, knowledge of the TRU Programme, expected availability and proximity to York or Cambridge. Workshop invitations were sent to identified subject matter experts with a 3-week notice to mitigate risk of low attendance. Invitations were sent to include the workshop agenda, which were tailored according to the type of workshop organised. Two separate workshop agendas were determined, one for trialling the method and one for gathering feedback.

The agenda for the workshop for trialling the AIR method is as follows.

(a) Introductions. Participants were asked to introduce themselves to the group (5 min).

(b) Workshop aim. The facilitator explained the intended outcome of the workshop and briefly explained the structure of the session (10 min).

(c) AIR method explanation. The facilitator explained the AIR method step by step using industry-specific examples. Participants were briefed on DTs in relation to the TRU Programme (40 min).

(d) Implementation of the AIR method. Using the developed web application, participants were asked to support the facilitator with completing the AIR method for the organisational objective 'improve customer satisfaction' (180 min).

(e) Next steps. Participants were given access to the web application and encouraged to continue submitting inputs outside the workshop. Participants were asked to return for a second workshop to provide feedback on results and the AIR method in general (5 min).

The agenda for the workshop for capturing industry feedback is as follows.

(a) Introductions. Participants were asked to introduce themselves to the group (5 $\mathrm{min}$ )

(b) Case study. The facilitator reintroduced the case study aims and presented the results (45 $\mathrm{min})$.

(c) Feedback discussion. Participants were asked to evaluate the results and discuss the potential value to the industry and potential improvements that could be made to the AIR method (50 min).

(d) Next steps. Participants were asked to complete an anonymous survey and were thanked for their support (5 min).

\subsection{Milestones 2 and 3: organisational objectives}

Milestones 2 and 3 involve the identification of all organisational objectives set by Network Rail. A total of 41 Network Rail documents amounting to over 2000 pages were identified for the assessment. Extraction of organisational objectives was semiautomated using a Python script that pulls out a sentence when it contains one of the following text strings: 'objective', 'goal' or 'target'. The three text strings were derived from analysing organisational objectives initially extracted using a manual 
Smart Infrastructure and Construction

Volume 174 Issue 2
Informing the information requirements

of a digital twin: a rail industry case

study

Johnson, Heaton, Yule et al. approach was applied to Network Rail Limited's Annual Report and Accounts 2019 (Network Rail, 2019b). Over 95\% of the organisational objectives manually extracted from this document contained at least one of these keywords. It was assumed that the remaining 40 documents would use similar language and so at least $95 \%$ of all objectives would be identified using the automated approach. Running the Python script on all 41 documents outputted a total of 59 organisational objectives, taking a total of $2 \mathrm{~h}$ to review and collate, $20 \mathrm{~h}$ including the time to write and check the Python code. In contrast, completing the manual extraction of organisation objectives on Network Rail's annual report took approximately $8 \mathrm{~h}$ to collect, review and document. Using this as a measure of effort, it was estimated that completing manual extraction process on all documents would have taken approximately 2 weeks to complete. The Python'generated' organisational objectives were sense-checked with Network Rail for validity. Future research should look to compare the accuracy of results by analysing difference in outputs between completing the manual process in full and the Python outputs. Figure 5 presents the distribution of objectives according to Network Rail's corporate initiatives: reliable, safe, growing and efficient. Samples of extracted Network Rail organisational objectives are displayed in Table 2. The complete list of extracted organisational objectives is contained in Table S1 in the online supplementary material.

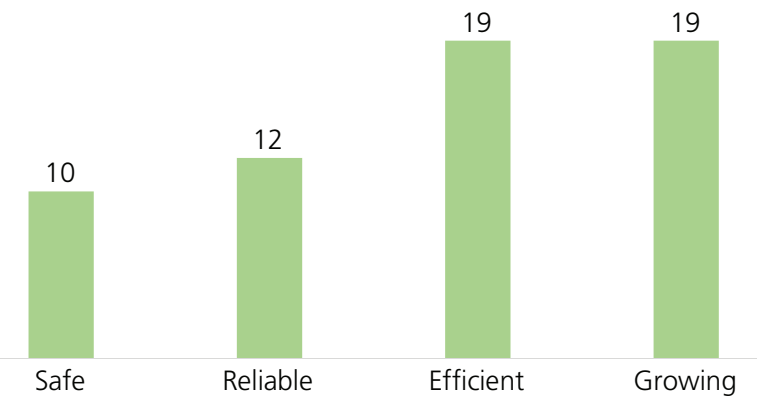

Figure 5. Organisational objective count according to the core initiatives of Network Rail (2018)

Table 2. Samples of Network Rail organisational objectives

\begin{tabular}{|ccc|} 
Organisational objective & $\begin{array}{c}\text { Target } \\
\text { completion } \\
\text { year }\end{array}$ & $\begin{array}{c}\text { Corporate } \\
\text { initiative } \\
\text { category }\end{array}$ \\
\hline $\begin{array}{c}\text { Reduce risk of train accidents } \\
\text { by } 10 \%\end{array}$ & 2024 & Safe \\
$\begin{array}{c}\text { Increase biodiversity on and } \\
\text { around the railway }\end{array}$ & 2024 & Growing \\
$\begin{array}{c}\text { Reduce energy consumption } \\
\text { by 18\% }\end{array}$ & 2024 & Growing \\
$\begin{array}{c}\text { Reduce the frequency of } \\
\text { temporary speed restrictions } \\
\text { Save } f 3.5 \text { billion through } \\
\text { developing and applying } \\
\text { efficiencies }\end{array}$ & 2020 & Reliable \\
\hline
\end{tabular}

\subsection{Milestones 4 and 5: information requirements}

Information requirements are produced when completing steps 2-5 of the AIR method. These requirements are captured by undertaking collaborative workshops with various industry professionals. This presents a challenge to communicate the research so that the process is understandable to all. A second challenge is to record CSFs, PLQs and information requirements in a way that does not detrimentally impact the flow of the workshop. These challenges were addressed by the creation of a web application using Microsoft Power Apps (corresponding to milestone 4). The web app aligns with the AIR method and enabled seamless documentation of workshop outputs.

Using the web application, a total of five workshops were held, attended by 24 rail industry professionals in total. Each workshop had on average five participants with similar expertise and seniority. Two workshops were attended by rail engineers, two by senior management professionals and one by professionals who manage at the national strategic level. Over the course of $3 \mathrm{~h}$, workshop participants were asked to complete the process against the organisational objective 'improve customer satisfaction'. CSFs, PLQs, FIRs and AIRs were captured using the application, and inputs were submitted only after reviewing the respective clarification statement for validity. Workshops were well attended, receiving good engagement from all levels of Network Rail.

\subsection{Milestone 6: AIR method industry application review}

Application of the AIR method was finalised by reviewing outputs obtained from workshops and gathering feedback from industry professionals, with emphasis on the potential benefits to DTs. This was achieved by undertaking three collaborative workshops and an anonymous survey. The feedback received is presented in Section 6.3.

\section{Results}

This section presents the case study results, including industry feedback on the AIR method. Information requirements gathered during the case study were manually captured using the developed web application (Figure 6) during a workshop setting. The web application was designed to structure data in a consistent table format. The structure of the data is critical to establishing the 'line of sight', which helps understand information requirements that would be impacted by a change to any given organisational objective.

\subsection{AlR method outputs}

A snapshot of outputs from the case study is provided in Tables 3-5 for the organisational objective 'improve customer satisfaction'. The full set of results is provided as supplementary information and contained in Tables S2-S5 in the online supplementary material.

\subsection{Industry benefits}

A total of nine industry professionals were asked to return for a final workshop to provide feedback on the AIR method. Feedback was 


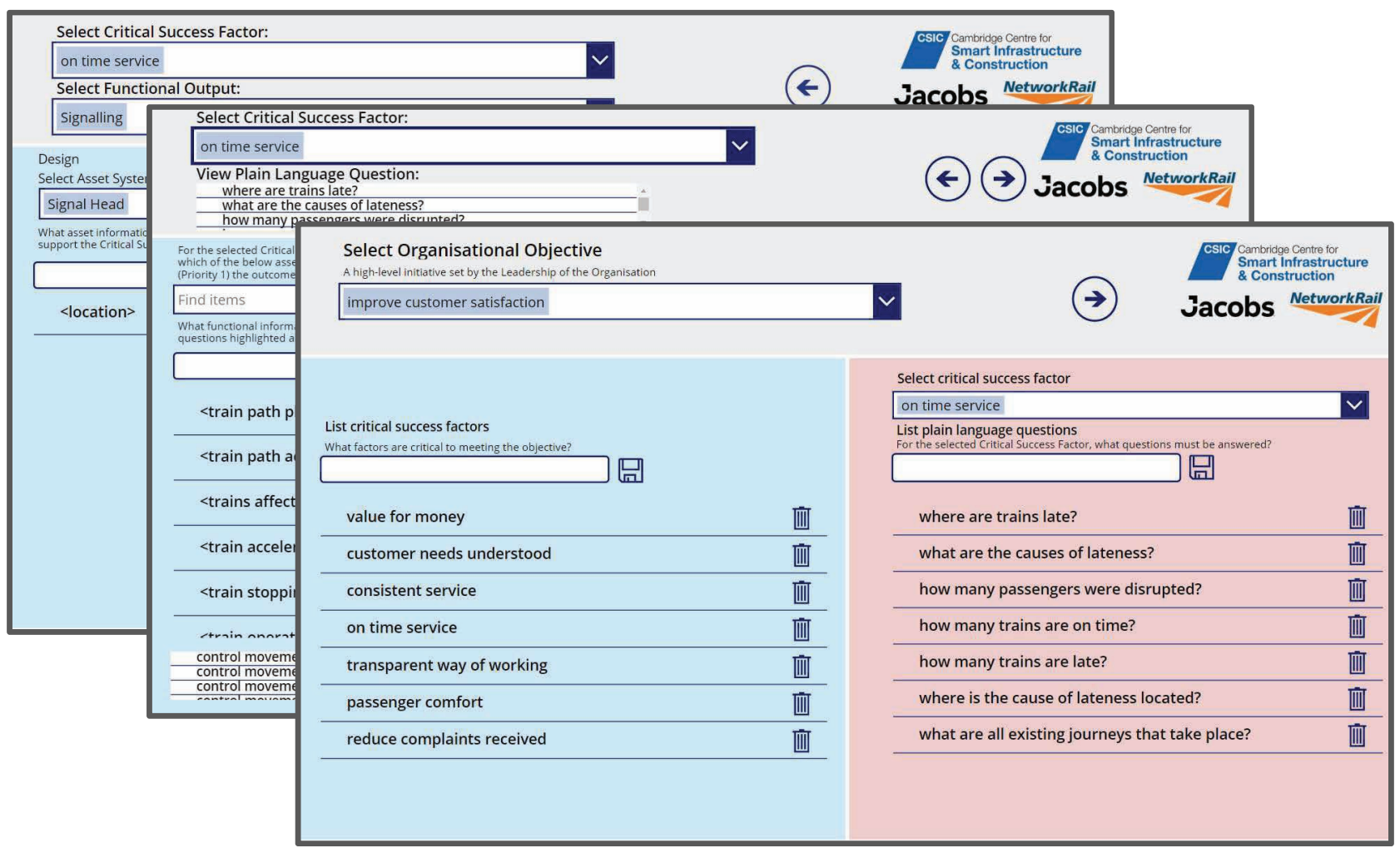

Figure 6. Screenshot of the web application

Table 3. Samples of OIRs

\begin{tabular}{|c|c|c|c|}
\hline Organisational objective & CSF & PLQ & OIR \\
\hline Improve customer satisfaction & On-time service & Where are trains late? & $<$ Location of train when delayed $>$ \\
\hline Improve customer satisfaction & On-time service & $\begin{array}{l}\text { How many passengers were } \\
\text { disrupted? }\end{array}$ & $<$ Measure of passengers disrupted $>$ \\
\hline Improve customer satisfaction & $\begin{array}{l}\text { Customer needs } \\
\text { understood }\end{array}$ & $\begin{array}{l}\text { Typical connections and have } \\
\text { they been met? }\end{array}$ & $<$ Connections made at each train station $>$ \\
\hline Improve customer satisfaction & $\begin{array}{l}\text { Passenger } \\
\text { comfort }\end{array}$ & $\begin{array}{l}\text { How many passengers can } \\
\text { access Wi-Fi? }\end{array}$ & $<$ Measure of Wi-Fi connectivity on route $>$ \\
\hline Improve customer satisfaction & $\begin{array}{l}\text { Passenger } \\
\text { comfort }\end{array}$ & $\begin{array}{l}\text { How many passengers are } \\
\text { seated against those standing? }\end{array}$ & $\begin{array}{l}<\text { Measure of passengers seated on their journey }> \\
<\text { measure of passengers standing on their journey }>\end{array}$ \\
\hline
\end{tabular}

Table 4. Samples of FIRs

\section{CSF}

On-time service

On-time service

On-time service

On-time service

On-time service

\section{Functional output}

Control movement(s) of traffic Control movement(s) of traffic Control movement(s) of traffic Control movement(s) of traffic Control movement(s) of traffic

\section{FIR}

$<$ Train path planned $>$

$<$ Trains affected $>$

$<$ Train acceleration $>$

$<$ Train stopping distance>

$<$ Trains affected $>$

Table 5. Samples of AIRs

$\begin{array}{lll}\text { Functional output } & \text { Asset system } & \text { AIR } \\ \text { Control movement(s) of traffic } & \text { Interlocking } & \text { < Type of interlocking system> } \\ \text { Control movement(s) of traffic } & \text { Interlocking } & <\text { Age> } \\ \text { Control movement(s) of traffic } & \text { Interlocking } & <\text { Location> }\end{array}$


provided with emphasis on the potential benefits to the rail industry and DTs by reviewing the expected impact that the AIR method would have on their day-to-day decisions if implemented in full. Benefits captured can be separated into two types: discrete benefits that require completion of a select number of steps without obligation to implement the AIR method in full and long-term benefits realised when fully embedding the AIR method into the organisation. Tables 6 and 7 present the identified benefits graded either 'low', 'medium' or 'high' according to the expected impact on day-to-day decisions. The graded impacts on day-to-day decisions were reviewed by Network Rail industry professionals.

\subsection{Industry feedback}

A total of 24 industry professionals were asked to provide comments, positive or negative, on the AIR method and the workshop content by way of an anonymous survey using SurveyMonkey. Seventeen people responded in total, ten of which answered 'extremely useful' to the question, 'Is the AIR method useful to Network Rail?'; six, 'useful'; and one, 'not useful'; 100\% of questionnaire responses stated that they were happy with the content covered in the workshop.

In addition, participants were asked to return for a final workshop to provide feedback on the AIR method with emphasis on

\section{Table 6. Discrete benefits}

$\begin{aligned} & \text { Validates strategic alignment across the organisation } \\ & \text { Achieved by } \\ & \text { Completing step } 1 \text { of the AIR method } \\ & \text { The organisational objectives identified could be assessed to clarify alignment with overall industry initiatives of } \\ & \text { putting passengers first and having a better railway for a better Britain }\end{aligned}$
$\begin{aligned} & \text { Potential value to DTs and the } \\ & \text { Medium - improve current understanding on the ability of the rail industry to monitor, assess and cascade } \\ & \text { targets to different areas of the business }\end{aligned}$
$\begin{aligned} & \text { Improves management and design of UK rail data systems } \\ & \text { Completing steps 1-4 of the AIR method } \\ & \text { How? } \\ & \text { Data system designers can utilise a greater understanding of interconnectivity between requirements to help } \\ & \text { optimise interfaces between different data systems, thereby unlocking the potential for improved intelligent } \\ & \text { analysis }\end{aligned}$
$\begin{aligned} & \text { Potential value to DTs and the } \\ & \text { rail sector }\end{aligned}$

Table 7. Long-term benefits

\section{Facilitates creation of a holistic information system}

How? Information requirements are identified and validated through collaborative workshops attended by a diverse number of participants. Participants are selected to ensure variety of background, expertise and seniority such that each offers a different perspective on what is important. Having broad engagement from all areas of the business also exposes the many different information systems that are already available and are often niche and difficult to discover. Undertaking this type of engagement coupled with promoting a strategic mindset ensures that a wide mix of information requirements are captured against each objective. On completion, the process can output an 'interface map' between the industry data systems as well as outline what decision(s) each piece of information will inform

Potential value to DTs and the High - the AIR method highlights the interfaces between rail data systems for an individual asset - a critical rail sector step to unlocking full potential of DTs, thus providing designers and operators with a more rounded view on the impact that their decisions have on the railway

\section{Establishes alignment between organisational strategy and information captured at the asset level}

How?

The AIR method utilises a top-down approach that starts the process by identifying all organisational objectives. Then, for each objective, the process considers how different railway functions can influence the desired outcome. Alignment is then established at the asset level by reviewing which asset systems are needed to achieve each functional output and how these assets can impact the outcome. The end outcome is an AIR that supports a functional output that achieves the organisational objective, thus providing clear alignment from strategy to activity on the ground

Potential value to DTs and the Medium - improves the ability of a DT to inform performance improvement rail sector

\section{Lays the groundwork for appropriate, relevant and effective asset information}

How?

Steps 1-3 of the AIR method encourage a type of thinking that goes back to the core fundamentals of successful railway operation. Following the process step by step encourages collaborators to take a step back, preventing common cognitive fallacies such as tunnel vision, and helps capture necessary information that might have been overlooked previously. This approach also highlights non-critical information that is currently being captured but is not needed

Potential value to DTs and the High - delay in action could result in significant information loss, which will compromise future understanding rail sector and long-term sustainability of maintaining a DT 
Smart Infrastructure and Construction

Volume 174 Issue 2
Informing the information requirements

of a digital twin: a rail industry case

study

Johnson, Heaton, Yule et al. potential value to the rail industry. The benefits identified are provided in Section 6.2. Overall, feedback captured during the workshops was positive and there was unanimous approval of the logic imposed by the AIR method to develop a solid digital environment foundation. However, there were concerns about practicality and scalability. Key feedback received during the workshops is displayed in Figure 7. Corresponding opportunities are presented in Section 7.

\section{Limitations and future research}

Feedback given by industry professionals provides several opportunities for future research in developing the AIR method further. It is unlikely that an organisation would apply the AIR method in full until some of these challenges have been addressed. Identified challenges and associated opportunities are presented in Figure 8. In addition to potential improvements to the compatibility of the method with the industry, it was also noted that some participants did have issues obtaining access to the Power Apps application outside the workshop environment. Future research should consider alternative software applications that may improve application accessibility for participants.

\section{Conclusion}

Adaptations made to the AIR method improved the practicality of applying the approach in the industry. Integration of text-scraping techniques to identify organisational objectives led to a significant
'Process will significantly improve industry's existing decision-making processes through design, construction and operation

'The rail sector should implement this method no was there is a lot of data currently not being captured that is needed'

'Information requirements should be compared against the strategic decision flow to ensure all requirements are captured'
'Complete gap analysis between outputted asset information requirements against network rail data governance report'

'The method should implement a validation step as and when information requirements are inputted'

'Method would need to be implemented strategically as completion of process in full would be a monumental task'

Figure 7. Rail industry feedback on the AIR method

Limitations

Future research opportunities
Completion of the process in full would be a monumental task requiring significant resources

Scalability is constrained by the need to complete collaborative workshop sessions with industry experts who have limited availability

Implementation of the process and realisation of associated benefits would require significant cultural shift in the organisation

Implementation of the AIR method does not produce a distinct measurable output that is clear and obvious
Research how the AIR method could build on/ complement information systems and processes that already exist in the industry

Research potential further adaptations needed to facilitate transformation from undertaking traditional workshop sessions to short 'valueadding' sprints

Development of a complementary process that calculates and aggregates the value unlocked during each step of the AIR method

Business change could be facilitated by focusing application of the AIR process on a specific area of business and broaden scope incrementally

Further develop the AIR method to capture the value dependency of information requirements to the organisation. This would enable organisations to calculate the value of their data and, therefore, the value of their DT

Figure 8. AIR limitations and future research opportunities 
Smart Infrastructure and Construction

Volume 174 Issue 2
Informing the information requirements

of a digital twin: a rail industry case

study

Johnson, Heaton, Yule et al. improvement in efficiency, preventing the need to undertake an arduous manual extraction exercise. In addition, the web application provides an adequate platform to distil the innovative concept into a process that can be easily repeated. Power Apps, the software package chosen to develop the application, did cause accessibility issues to participants external to the organisation, and so other alternative software may need to be considered in the future.

Overall, the AIR method received positive feedback with a unanimous appreciation of its focus on developing the foundation of a digital environment, which is often overlooked but is crucial to achieving the Gemini principles. There is a lot of discussion in the industry around complex digital initiatives such as DTs, which are not compatible with existing industry practices of information management. Completion of the AIR method ensures that the industry is well positioned for digital transformation. Irrespective of deploying a DT, the approach will add value to designers', operators' and maintainers' current decision-making processes, thereby helping improve the railway for its passengers. It is unlikely that an organisation would apply the AIR method in full, and so the identification of discrete benefits suggests that value could instead be incrementally realised through completion of individual steps, making it possible to deploy the AIR method iteratively through a number of short 'value-adding' sprints.

Reflecting on research question 1 , the literature review noted a set of methodologies from the domain of DTs, RE and BIM that provide an approach to the development of information requirements. Due to the wealth of knowledge that already exists in the identification of information requirements, it was decided to adopt an existing approach. The adoption was driven by the need for a DT to have a purpose stated within the Gemini report. The methodology presented in Figure 2 was selected as an appropriate starting point, as it aligns closely with this philosophy by establishing a purpose through understanding organisational and functional objectives.

Reflecting on research question 2, one of the unique aspects of this research was that the authors were fully embedded within the industry. Several interviews were conducted to gain an industry insight on the 'practical' application of the research within a 'live' project. Feedback was both comprehensive and specific for the researcher to act on. As an example, adaptation 1 was adopted from the feedback regarding the resource-intensive nature of developing an asset classification system.

Network Rail, the case study partner, is currently in the early stages of developing a DT and concluded that the implementation of the AIR method would ensure that information contained in the DT remains relevant, has a clear purpose and is able to inform day-to-day decisions in operation, design and build.

The method is still in its infancy, and further research is needed to continue the progress made by this case study by addressing the opportunities outlined in Figure 8.

\section{Acknowledgements}

This project was funded by an Innovate UK grant to the Centre for Smart Infrastructure and Construction (Grant Number 920035). The authors would like to acknowledge Jacobs, the University of Cambridge Centre for Smart Infrastructure and Construction and Network Rail, who collectively supported this project.

\section{REFERENCES}

Ackoff RL (1967) Management misinformation systems. Management Science 14(4): 147-156, https://doi.org/10. 1287/mnsc.14.4.B147.

Ashworth S, Tucker M and Druhmann C (2016a) The role of FM in preparing a BIM strategy and Employer's Information Requirements (EIR) to align with client asset management strategy. Proceedings of the 15th EuroFM Research Symposium, Milan, Italy, pp. 8-9. See https:/www.researchgate.net/publication/301776904 (accessed 18/12/2020)

Ashworth S, Tucker M and Druhmann C (2016b) Employer's Information Requirements (EIR): a BIM case study to meet client and facility manager needs. In EFMC 2017: Research Papers for EUROFM's 16th Research Symposium, 25-28 April 2017 in Madrid, Spain (Nielsen SB, Jensen PA and Brinkø R (eds)). Polyteknisk Forlag, Lyngby, Denmark, pp. 112-121.

Becerik-Gerber B, Jazizadeh F and Li N (2011) Application areas and data requirements for BIM-enabled facilities management. Journal of Construction Engineering and Management 138: 431-442, https://doi. org/10.1061/(ASCE)CO.1943-7862.0000433.

Boje C, Guerriero A, Kubicki S and Rezgui Y (2020) Toward a semantic construction digital twin: directions for future research. Automation in Construction 114: article 103179, https://doi.org/10.1016/j.autcon. 2020.103179 .

Butkovic B, Heesom D and Oloke D (2019) The need for multi-LOD 4D simulations in construction projects. Journal of Information Technology in Construction 24: 256-272, https://doi.org/10.36680/j. itcon.2019.014.

Cavka HB, Staub-French S and Poirier EA (2017) Developing owner information requirements for BIM-enabled project delivery and asset management. Automation in Construction 83: 169-183, https://doi.org/ 10.1016/j.autcon.2017.08.006.

CDBB (Centre for Digital Built Britain) (2019) The Gemini Principles. CDBB, Cambridge, UK. See https://www.cdbb.cam.ac.uk/ Resources/ResoucePublications/TheGeminiPrinciples.pdf (accessed 18/12/2020).

Gürdür D and Asplund F (2018) A systematic review to merge discourses: interoperability, integration and cyber-physical systems. Journal of Industrial Information Integration 9: 14-23, https://doi.org/10.1016/j. jii.2017.12.001.

Heaton J, Parlikad AK and Schooling J (2019) A building information modelling approach to the alignment of organisational objectives to asset information requirements. Automation in Construction 104: 14-26, https://doi.org/10.1016/j.autcon.2019.03.022.

ISO (International Organization for Standardization) (2014) ISO 55000:2014: Asset management - overview, principles and terminology. ISO, Geneva, Switzerland.

ISO (2018a) BS EN ISO 19650-1:2018: Organization and digitization of information about buildings and civil engineering works, including building information modelling (BIM) - Information management using building information modelling - Part 1: Concepts and principles. ISO, Geneva, Switzerland.

ISO (2018b) BS EN ISO 19650-2:2018: Organization and digitization of information about buildings and civil engineering works, including building information modelling (BIM) - Information management 
Smart Infrastructure and Construction

Volume 174 Issue 2
Informing the information requirements

of a digital twin: a rail industry case

study

Johnson, Heaton, Yule et al. using building information modelling - Part 2: Delivery phase of the assets. ISO, Geneva, Switzerland.

Kelly G, Serginson M, Lockley S, Dawood N and Kassem M (2013) BIM for facility management: a review and a case study investigating the value and challenges. In CONVR 2013: Proceedings of the 13th International Conference on Construction Applications of Virtual Reality, 30-31 October 2013, London (Dawood N and Kassem M (eds)). Teesside University, Middlesbrough, UK, pp. 191-199. See http://itc.scix.net/ data/works/att/convr-2013-20.pdf (accessed 18/12/2020).

Leng J, Zhang H, Yan D et al. (2019) Digital twin-driven manufacturing cyber-physical system for parallel controlling of smart workshop. Journal of Ambient Intelligence and Humanized Computing 10(3): 1155-1166, https://doi.org/10.1007/s12652-018-0881-5.

Lu VQ, Parlikad AK, Woodall P, Ranasinghe GD and Heaton J (2019) Developing a dynamic digital twin at a building level: using Cambridge Campus as case study. In International Conference on Smart Infrastructure and Construction 2019 (ICSIC): Driving Datainformed Decision-making (DeJong MJ, Schooling JM and Viggiani GMB (eds)). ICE Publishing, London, UK, pp. 67-75.

Lu Q, Parlikad AK, Woodall P et al. (2020a) Developing a digital twin at building and city levels: case study of West Cambridge Campus. Journal of Management in Engineering 36(3): article 05020004, https://doi.org/10.1061/(ASCE)ME.1943-5479.0000763.

Lu Q, Xie X, Parlikad AK and Schooling JM (2020b) Digital twin-enabled anomaly detection for built asset monitoring in operation and maintenance. Automation in Construction 118: article 103277, https:// doi.org/10.1016/j.autcon.2020.103277.

Madni A, Madni C and Lucero S (2019) Leveraging digital twin technology in model-based systems engineering. Systems 7(1): article 7, https://doi.org/10.3390/systems 7010007.

Moore WJ and Starr AG (2006) An intelligent maintenance system for continuous cost-based prioritisation of maintenance activities. Computers in Industry 57(6): 595-606, https://doi.org/10.1016/j. compind.2006.02.008

Navendren D, Mahdjoubi L, Shelbourn M and Mason J (2015) An examination of clients and project teams developing information requirements for the Asset Information Model (AIM). WIT Transactions on the Built Environment 149: 169-179, https://doi.org/ 10.2495/BIM150151.

NBS (2015) Uniclass Hierarchy Tables. NBS, Newcastle upon Tyne, UK. See https://www.thenbs.com/our-tools/uniclass-2015 (accessed 15/12/ 2019).
Network Rail (2018) Strategic Business Plan - Summary. Network Rail, London, UK. See https://cdn.networkrail.co.uk/wp-content/uploads/ 2018/02/CP6-Strategic-Business-Plan-Comprehensive-ExecutiveSummary.pdf (accessed 21/12/2019).

Network Rail (2019a) Transpennine Upgrade Programme. Network Rail, London, UK. See https://www.networkrail.co.uk/running-the-railway/ railway-upgrade-plan/key-projects/transpennine-route-upgrade/ (accessed 01/12/2019).

Network Rail (2019b) Network Rail Limited's Annual Report and Accounts 2019. Network Rail, London, UK. See https://cdn. networkrail.co.uk/wp-content/uploads/2019/07/Annual-report-andaccounts-2019.pdf. (accessed 11/12/2019).

NIC (National Infrastructure Commission) (2017) Data for the Public Good. NIC, London, UK.

Patacas J, Dawood N, Vukovic V and Kassem M (2015) BIM for facilities management: evaluating BIM standards in asset register creation and service life. Journal of Information Technology in Construction 20: 313-331.

Patacas J, Dawood N, Greenwood D and Kassem M (2016) Supporting building owners and facility managers in the validation and visualisation of asset information models (AIM) through open standards and open technologies. Journal of Information Technology in Construction 21: 434-455.

Rockart JF (1979) Chief executives define their own data needs. In Harvard Business Review, March, pp. 81-93. See https://hbr.org/ 1979/03/chief-executives-define-their-own-data-needs (accessed 18/12/2020).

Souza V, Cruz R, Silva R, Lins S and Lucena V (2019) A Digital Twin architecture based on the industrial Internet of Things technologies. Proceedings of the 2019 IEEE International Conference on Consumer Electronics (ICCE 2019), Las Vegas, NV, USA.

Tao F, Sui F, Liu A et al. (2019) Digital twin-driven product design framework. International Journal of Production Research 57(12): 3935-3953, https://doi.org/10.1080/00207543.2018.1443229.

Wetherbe JC (1991) Executive information requirements: getting it right. MIS Quarterly 15(1): 51-65, https://doi.org/10.2307/249435.

Wetherbe JC and Davis GB (1983) Developing a long-range information architecture. In Proceedings of the 1983 AFIPS National Computer Conference. Anaheim, CA, USA, pp. 261-269.

Zachman JA (1982) Business systems planning and business information control study: a comparison. IBM Systems Journal 21(1): 31-53, https://doi.org/10.1147/sj.211.0031.

\section{How can you contribute?}

To discuss this paper, please email up to 500 words to the editor at journals@ice.org.uk. Your contribution will be forwarded to the author(s) for a reply and, if considered appropriate by the editorial board, it will be published as discussion in a future issue of the journal.

Proceedings journals rely entirely on contributions from the civil engineering profession (and allied disciplines). Information about how to submit your paper online is available at www.icevirtuallibrary.com/page/authors, where you will also find detailed author guidelines. 